\title{
Effects of three spinal stabilization techniques on activation and thickness of abdominal muscle
}

\author{
Byeong-Jo Kim, Su-Kyoung Lee* \\ Department of Physical Therapy, College of Nersing and Healthcare Science, Dong-Eui University, Korea
}

In this study, we examine the thickness of the abdominal muscle and its activity during the performance of the three drawing-in methods. The subjects were 20 healthy male and female students in their 20 s. Using ultrasonography and electromyography, the experimenter measured the thickness of the transversus abdominis $(\operatorname{Tr} A)$ muscle, internal oblique (IO) muscle and external oblique (EO) muscle. The ultrasonography measurements for the drawing-in manoeuver (DI), abdominal bracing, and posterior pelvic tilt (PT) techniques were $0.64 \pm 0.20$, $0.54 \pm 0.15$, and $0.46 \pm 0.12$, respectively, with significant differences for the TrA. The electromyography results of the DI, SA, and PT techniques were $4.35 \pm 1.72,3.00 \pm 1.48$, and $2.70 \pm 1.52$, respectively, for the 10 . There was a significant difference in the DI, SA, and PT techniques for the EO $(5.10 \pm 3.30,3.85 \pm 3.89,2.25 \pm 1.29$, respectively). The DI method activated the oblique abdominal muscles, but there was no great change in their thickness; the TrA, however, was selectively strengthened through changes in its thickness.

Keywords: Spinal stabilize, Drawing-in manoeuver, Abdominal muscle thickness, Abdominal muscle activation

\section{INTRODUCTION}

Spinal stability is important for prevention and treatment of lumbar damage (McGill, 2001), and requires concurrent activity of all trunk muscles around the lumbar region (Lehman et al., 2005: Marshall and Murphy, 2005). The spinal muscles used for spinal stability are divided into global muscles, which are large muscles located on the surface of the abdomen and lumbus and are engaged in overall stability, and local muscles, which are intrinsic muscles situated deep in the abdomen and lumbus, are directly connected to the spine and engage in fine adjustment of the spine and stability of the spinal segments (Bergmark, 1989). Concurrent activity between the global and local muscles maintains the spine in a stabilized condition (Marshall and Murphy, 2005: Stevens et al., 2007), which is essential for physical posture, balance and recovery of stability (Duarte et al., 2002). Loss of this trunk control function is a factor for body misalignment, decrease in upper and lower extremity motor function and impairment in balance ad- justment, gait ability and activities of daily living (Verheyden et al., 2006). Therefore, trunk control can be used to evaluate balance, gait and recovery in daily routines (Hsieh et al., 2002).

Stabilization exercises are conducted to adjust force when the patient's posture is unstable and to control movements consciously and unconsciously so that the spine maintains a neutral position, which is the best posture for the spine to adjust to an external load. Both global trunk and segment deep muscles play critical roles in providing stability and maintaining the upright posture (Kisner and Colby, 2016), and is an intervention that prevents repetitive micro-damage of the muscles around the spine and degenerative change of the spinal joints (Richardson et al., 1999). It is used as an essential therapeutic method for low-back pain patients to recover trunk control ability (Maffey-Ward et al., 1996).

The three methods used to activate the stabilizer muscle system in the lumbar vertebra include a drawing-in manoeuver (DI) to pull the navel towards the spine, abdominal bracing (AB) to splay the lumbar region laterally by fixing the abdominal muscles and a
${ }^{*}$ Corresponding author: Su-Kyoung Lee (iD http://orcid.org/0000-0002-4916-2188 Department of Physical Therapy, College of Nersing and Healthcare Science, DongEui University, 176 Eomgwangno, Busanjin-gu, Busan 47340, Korea Tel: +82-51-890-4223, Fax: +82-505-182-6881, E-mail: ptlsk@deu.ac.kr Received: January 9, 2017 / Accepted: April 15, 2017
This is an Open Access article distributed under the terms of the Creative Commons Attribution Non-Commercial License (http://creativecommons.org/licenses/by-nc/4.0/) which permits unrestricted non-commercial use, distribution, and reproduction in any medium, provided the original work is properly cited. 
posterior pelvic tilt (PT) to make the pelvis tilt posteriorly in a positive manner and the lumbar vertebra even. Among them, the first method activates the transversus abdominis $(\operatorname{Tr} A)$, minimizing contraction of the oblique abdominal or not contracting the muscle (Kisner and Colby, 1999). As a technique to measure this, ultrasonography is a useful noninvasive tool to measure the size and activity conditions of deep trunk muscles, such as the $\operatorname{Tr} A$ and multifidus (Kwon et al., 2011). Ultrasonography can observe an object directly on a real-time basis and enables fast measurement and repetitive tests without the risk of radiation exposure (Hedrick et al., 1995; Rumack et al., 1998). In this study, we examine the thickness of the abdominal muscle and its activity during the performance of the three drawing-in methods.

\section{MATERIALS AND METHODS}

\section{Participants}

The subjects were 20 young male university students aged between 21 and 30 years. The procedures of this study were harmless to the human body. All subjects read and signed a written consent form. They listened to an account of the study's purpose and methods, understood the study content and consented to participate in this experiment (Table 1).

\section{Design}

Using ultrasonography and electromyography, the experimenter measured the thickness of the $\operatorname{Tr} A$, internal oblique (IO) and external oblique (EO) muscle. Also measured was the activity of the $\mathrm{IO}$ and $\mathrm{EO}$ while the subject was performing the three drawing-in methods. The three spinal stabilization methods-DI, AB, and PT-were performed 3 times randomly. Each motion was maintained for $5 \mathrm{sec}$.

Drawing-in manoeuver: The subject lay in a supine position on a bed with the knee joint flexed at $90^{\circ}$. Both hands were placed beside the head, and the eyes were fixed on one point on the ceiling. As the subject breathed out, the navel was posteriorly pulled up.

Abdominal bracing: In the same posture as described above, the

Table 1. Characteristics of study participants $(n=20)$

\begin{tabular}{lc}
\hline Characteristic & Value \\
\hline Sex, male:female & $5: 15$ \\
Age $(\mathrm{yr})$ & $20.95 \pm 1.14$ \\
Height $(\mathrm{cm})$ & $165.10 \pm 8.46$ \\
Weight $(\mathrm{kg})$ & $57.10 \pm 8.94$ \\
\hline
\end{tabular}

Values are presented as number or mean \pm standard deviation. subject breathed out and pulled in the navel with constant pressure.

Posterior pelvic tilt: In the same posture as described above, the subject breathed out, had the lumbus evenly on the bed and the pelvis was pulled back.

\section{Measurements and statistical analysis}

Changes in the thickness of the $\mathrm{IO}$ and $\mathrm{EO}$ were analysed using ultrasonography (F31, Hitachi-Aloka Medical., Tokyo, Japan) while the subjects were resting and in a state of three draw-in method. Ultrasonography was conducted by referring to previous studies. Ultrasonographic imaging was obtained using a 10-MHz linear probe (UST-5413), with the midpoint of the transducer placed along the midaxillary line in the transverse plane just above the right iliac crest (Hodges et al., 2003). A wireless surface electromyography (TeleMyo 2400T, Noraxon Co., Scottsdale, AZ, USA), was used to obtain measurements. Each muscle's surface electrode was attached to the middle area of the belly where the muscles were most activated in parallel with the direction of the muscle fibres in a manual muscle test. The interval between the two electrodes was maintained at $2 \mathrm{~cm}$ to compare differences in potential between the two electrodes. All raw data from the electromyograph were transformed into root mean square and analysed as described below. In order to compare electromyography signals between subjects and between muscles, a standardization process was performed that assumed muscle contraction of certain motions as the reference voluntary contraction (RVC) and used the \%RVC based on the RVC (Cram et al., 1998) to standardize electromyography signals. A one-way analysis of variance (ANOVA) was utilized to examine changes in the thickness of abdominal muscles and changes in muscle activity when abdominal drawing-in techniques were performed. As a post hoc test, Fisher least significant difference (LSD) test was carried out. Statistical processing for data analysis was conducted using PASW Statistics ver. 18.0 (SPSS Inc., Chicago, IL, USA), and the significance level to verify statistical significance was set at 0.05 .

In this study, the experiment was conducted on a single force plate to examine movements and ground reaction forces in the feet while the subjects were standing up from sitting (BP600400, AMTI Co., Watertown, MA, USA), and data on vertical, forward-and-backward and side-to-side ground reaction forces were obtained. A one-way ANOVA approach was used to compare the changes according to the three angles and heights. Fisher LSD post hoc analysis was performed and the statistical significance level was set to 0.05 . 
Table 2. Comparison of abdominal muscle thickness according to three spinal stabilization techniques

\begin{tabular}{lccccc}
\hline & $\mathrm{DI}$ & $\mathrm{AB}$ & $\mathrm{PT}$ & $F$ & $P$-value \\
\hline TrA & $0.64 \pm 0.20$ & $0.54 \pm 0.15^{\dagger}$ & $0.46 \pm 0.12^{\ddagger}$ & 6.286 & $0.003^{*}$ \\
I0 & $0.88 \pm 0.40$ & $0.83 \pm 0.36$ & $0.80 \pm 0.25$ & 0.325 & 0.724 \\
E0 & $0.42 \pm 0.09$ & $0.40 \pm 0.10$ & $0.41 \pm 0.16$ & 0.098 & 0.907 \\
\hline
\end{tabular}

Values are presented as mean \pm standard deviation.

$\mathrm{DI}$, drawing-in; $\mathrm{AB}$, abdominal bracing; PT, pelvic posterior tilt; TrA, transversus abdominis; 10 , internal oblique; E0, external oblique.

${ }^{*} P<0.05$. Significant difference between $\mathrm{Dl}$ and $\mathrm{AB}(P<0.05)$. ${ }^{\dagger}$ Significant difference between $\mathrm{DI}$ and $\mathrm{PT}(P<0.05)$.

Table 3. Comparison of abdominal muscle activation according to three spinal stabilization techniques

\begin{tabular}{lccccc}
\hline & $\mathrm{DI}$ & $\mathrm{AB}$ & $\mathrm{PT}$ & $F$ & $P$-value \\
\hline $\mathrm{EO}$ & $4.35 \pm 1.72$ & $3.00 \pm 1.48^{\dagger}$ & $2.70 \pm 1.52^{\ddagger}$ & 6.169 & $0.004^{*}$ \\
EO & $5.10 \pm 3.30$ & $3.85 \pm 3.89$ & $2.25 \pm 1.29^{\ddagger}$ & 4.406 & $0.017^{*}$ \\
\hline
\end{tabular}

Values are presented as mean \pm standard deviation.

DI, drawing-in; $A B$, abdominal bracing; PT, pelvic posterior tilt; 10, internal oblique; EO, external oblique.

${ }^{*} P<0.05$. ${ }^{\top}$ Significant difference between $\mathrm{Dl}$ and $\mathrm{AB}(P<0.05) .{ }^{\star}$ Significant difference between $\mathrm{Dl}$ and $\mathrm{PT}(P<0.05)$.

\section{RESULTS}

The ultrasonography measurements for the drawing-in, $\mathrm{AB}$ and PT techniques were $0.64 \pm 0.20,0.54 \pm 0.15$, and $0.46 \pm 0.12$ $\mathrm{mm}$, respectively, with significant differences for the TrA muscle (Table 2). The post hoc test showed a significant difference between the drawing-in and $\mathrm{AB}$ techniques and between the drawing-in and PT techniques. The electromyography results of the drawing-in, $\mathrm{AB}$, and PT techniques were $4.35 \% \pm 1.72 \%, 3.00 \% \pm$ $1.48 \%$, and $2.70 \% \pm 1.52 \%$ of RVC, respectively, for the IO abdominal. There was a significant difference in the drawing-in, $\mathrm{AB}$, and $\mathrm{PT}$ techniques for the $\mathrm{EO}$ abdominal $(5.10 \% \pm 3.30 \%$, $3.85 \% \pm 3.89 \%, 2.25 \% \pm 1.29 \%$ of RVC, respectively) (Table 3). The post hoc test showed a significant difference between the drawing-in and $\mathrm{AB}$ techniques and between the drawing-in and PT techniques for the IO abdominal and a significant difference between the drawing-in and PT techniques for the EO abdominal.

\section{DISCUSSION}

Three techniques are commonly employed in the clinical field to activate abdominal muscles, but their effects are not obvious. In this study, experiments were conducted to minimize activity of the internal and $\mathrm{EO}$ and to examine which of the three techniques resulted in the greatest thickness and activity of the TrA. The treatment goal of the drawing-in technique is to activate the $\operatorname{Tr} A$, minimizing contraction of the oblique muscles or not contracting those muscles. With coactivation of the $\operatorname{Tr} A$ and multifidus, the DI technique was more effective than $\mathrm{AB}$ and PT (Hodges and
Richardson, 1996). The DI increases internal pressure by moving the abdominal wall inward (Kisner and Corby, 2016), and for this reason is recommended for stabilization training. In the present study, ultrasonography showed significant changes in the thickness of the $\operatorname{Tr} \mathrm{A}$ compared to the internal and $\mathrm{EO}$ when using the DI method. Kisner and Colby (2016) also reported that activation of these muscles was minimized or not perceived when surface electrodes were attached to the rectus abdominis and $\mathrm{EO}$ prior to using the $\mathrm{DI}$ method. $\mathrm{AB}$ in contrast with the $\mathrm{DI}$ method showed activation of the oblique abdominal and stabilized the global muscles (Richardson et al., 1992). In the present study, activity of DI in both the internal and $\mathrm{EO}$ was high using the $\mathrm{AB}$ and $\mathrm{PT}$ techniques with surface electromyography, and the activity of the $\operatorname{Tr} A$ significantly increased as shown by ultrasonography. This is judged to be because the activity of the IO and EO changed without changes to their thickness. The PT exercise largely activates the rectus abdominis, which is used for dynamic flexion of the trunk. This muscle is not considered a key stabilization muscle of the spine and is not regarded as important in stabilization training (Hodges and Richardson, 1997). This method is mostly used to perceive movement of the pelvis and lumbar vertebrae; stabilization muscles may be activated if the range of motion of the lumbus by pelvic tilting is spotted and the neutral location or the pelvic functional range of motion is known.

\section{CONFLICT OF INTEREST}

No potential conflict of interest relevant to this article was reported. 


\section{REFERENCES}

Bergmark A. Stability of the lumbar spine. A study in mechanical engineering. Acta Orthop Scand Suppl 1989;230:1-54.

Cram JR, Kasman GS, Holtz J. Introduction to surface electromyography. Maryland: Aspen; 1998.

Duarte E, Marco E, Muniesa JM, Belmonte R, Diaz P, Tejero M, Escalada F. Trunk control test as a functional predictor in stroke patients. J Rehabil Med 2002;34:267-272.

Hedrick WR, Hykes DL, Starchman DE. Ultrasound physics and instrumentation. 3rd ed, St Louis: Mosby; 1995.

Hodges PW, Pengel LH, Herbert RD, Gandevia SC. Measurement of muscle contraction with ultrasound imaging. Muscle Nerve 2003;27: 682-692.

Hodges PW, Richardson CA. Contraction of the abdominal muscle associated with movement of the lower limb. Phys Ther 1997;77:132-142.

Hodges PW, Richardson CA. Inefficient muscular stabilization of the lumbar spine associated with low back pain. A motor control evaluation of transversus abdominis. Spine (Phila Pa 1976) 1996;21:26402650.

Hsieh CL, Sheu CF, Hsueh IP, Wang CH. Trunk control as an early predictor of comprehensive activities of daily living function in stroke patients. Stroke 2002;33:2626-2630.

Kisner C, Colby LA. Therapeutic exercise for spinal segmental stabilization in low back pain. London: Churchill Livingston. 1999.

Kisner C, Corby LA. Therapeutic exercise: foundations and techniques, 6th ed. Philadelphia: F.A. Davis Company; 2016.
Kwon NH, Lee HO, Park DJ. The use of real-time ultrasound imaging for feedback during abdominal hollowing. J Korean Soc Phys Med 2011; 6:303-310.

Lehman GJ, Hoda W, Oliver S. Trunk muscle activity during bridging exercises on and off a Swiss ball. Chiropr Osteopat 2005;13:14.

Maffey-Ward L, Jull G, Wellington L. Toward a clinical test of lumbar spine kinesthesia. J Orthop Sports Phys Ther 1996;24:354-358.

Marshall PW, Murphy BA. Core stability exercises on and off a Swiss ball. Arch Phys Med Rehabil 2005;86:242-249.

McGill SM. Low back stability: from formal description to issues for performance and rehabilitation. Exerc Sport Sci Rev 2001;29:26-31.

Richardson C, Jull G, Toppenberg R, Comerford M. Techniques for active lumbar stabilisation for spinal protection: a pilot study. Aust J Physiother 1992;38:105-112.

Richardson CA, Jull GA, Hodges PW, Hides J. Therapeutic exercise for spinal segmental stabilization in low back pain: scientific basis and clinical approach. Edinburgh: Churchill Livingstone. 1999.

Rumack CM, Wilson SR, Charboneau JW. Diagnostic ultrasound. 2nd ed. St Louis: Mosby; 1998.

Stevens VK, Coorevits PL, Bouche KG, Mahieu NN, Vanderstraeten GG, Danneels LA. The influence of specific training on trunk muscle recruitment patterns in healthy subjects during stabilization exercises. Man Ther 2007;12:271-279.

Verheyden G, Vereeck L, Truijen S, Troch M, Herregodts I, Lafosse C, Nieuwboer A, De Weerdt W. Trunk performance after stroke and the relationship with balance, gait and functional ability. Clin Rehabil 2006;20:451-458. 